\title{
Análise do direito constitucional à saúde no sistema prisional brasileiro em tempos de
}

\section{pandemia}

\author{
Analysis of the constitutional right to health in the Brazilian prison system in times of pandemic \\ Análisis del derecho constitucional a la salud en el sistema penitenciario brasileño en tiempos de \\ pandemia
}

Recebido: 17/09/2021 | Revisado: 28/09/2021 | Aceito: 04/12/2021 | Publicado: 14/12/2021

\author{
Hugo Sarmento Gadelha ${ }^{1}$ \\ ORCID: https://orcid.org/0000-0001-9414-0554 \\ Universidad del Museo Social Argentino, Argentina \\ E-mail: hugoscurso@uol.com.br \\ Hiran Mendes Castro Filho ${ }^{2}$ \\ ORCID: https://orcid.org/0000-0002-1418-159X \\ Universidad del Museo Social Argentino, Argentina \\ E-mail: hirancastro@gmail.com \\ Agílio Tomaz Marques \\ ORCID: https://orcid.org/0000-0001-8364-5063 \\ Universidade Federal de Campina Grande, Brasil \\ E-mail: agiliotomaz@hotmail.com \\ Arthur Mendes Gasperini \\ ORCID: https://orcid.org/ 0000-0003-2358-497X \\ Faculdade Atenas, Brasil \\ E-mail: arthurgasperini@hotmail.com \\ Auzenir de Oliveira Abrantes Monteiro \\ ORCID: https://orcid.org/0000-0003-0363-620X \\ Universidade Federal de Campina Grande, Brasil \\ E-mail: auzenirabrantes@gmail.com \\ Suzana Araújo dos Santos \\ ORCID: https://orcid.org/0000-0001-5955-9421 \\ Universidade Federal de Campina Grande, Brasil \\ E-mail: suzana.santos2007@yahoo.com.br \\ Rosana Santos de Almeida \\ ORCID: https://orcid.org/0000-0001-8097-1074 \\ Universidade Federal de Campina Grande, Brasil \\ E-mail: rosana.santos@estudante.ufcg.edu.br \\ Matheus Matos Ferreira Silva \\ ORCID: https://orcid.org/0000-0002-3905-1951 \\ Universidade Federal de Campina Grande, Brasil \\ E-mail: matheusmatosfs@gmail.com
}

\begin{abstract}
Resumo
Esse artigo tem como objetivo analisar como está sendo efetivado o direito constitucional à saúde no contexto da pandemia da Covid-19 no sistema prisional. Ocorre que no Brasil, acontece um crescimento exponencial da população carcerária que vem se repetindo ano após ano, o que tem provocado um grande colapso no sistema prisional, e ao mesmo tempo isso tem gerado um descaso das autoridades em decorrência das diversas violações que acontecem diariamente dentro das prisões principalmente no que diz respeito ao direito à saúde nesse período pandêmico. A partir do surgimento do contágio do vírus tendo como principal medida o isolamento social e os cuidados de higiene pessoal, surgiu a preocupação em saber como seria alcançadas essas medidas dentro de um ambiente de condições degradantes como as penitenciarias brasileiras. Para a realização desse estudo foram utilizados o método de procedimento dedutivo, a pesquisa bibliográfica de natureza qualitativa a utilização da pesquisa documental. A partir da pesquisa concluiu-se que a pandemia se agravou com a precariedade já existente nos presídios como a superlotação, falta de estrutura, ambiente insalubre e falta de equipes médicas multidisciplinar para auxiliar nos cuidados médicos dos presos. Percebe-se que mesmo com a criação de políticas para a efetivação do direito à saúde dos apenados, elas não são colocadas em pratica e por sua vez, é preciso que sejam criadas estratégias para que se seja proporcionado nos presídios brasileiros uma prestação positiva do Estado principalmente nesse período de pandemia. Palavras-chave: Direito à saúde; Sistema prisional; Covid-19.
\end{abstract}

\footnotetext{
${ }^{1}$ Doutorando pela Universidad del Museo Social Argentino.

${ }^{2}$ Doutorando pela Universidad del Museo Social Argentino.
} 


\begin{abstract}
This article aims to analyze how the constitutional right to health is being implemented in the context of the Covi-19 pandemic in the prison system. In Brazil, there is an exponential growth of the prison population that has been repeated year after year, which has caused a major collapse in the prison system, and at the same time this has generated neglect by the authorities as a result of the various violations that take place daily within the prisons mainly with regard to the right to health in this pandemic period. From the emergence of the virus contagion, having as its main measure the social isolation and personal hygiene care, the concern arose to know how these measures would be achieved within an environment of degrading conditions such as Brazilian penitentiaries. To carry out this study, the method of deductive procedure, bibliographical research of a qualitative nature and the use of documentary research were used. From the research it was concluded that the pandemic was aggravated by the precariousness that already exists in prisons, such as overcrowding, lack of structure, unhealthy environment and lack of multidisciplinary medical teams to assist in the medical care of prisoners. It is noticed that even with the creation of policies for the realization of the inmates' right to health, they are not put into practice and, in turn, it is necessary that strategies be created so that a positive provision of the state is provided in Brazilian prisons. mainly in this period pandemic.
\end{abstract}

Keywords: Right to health, Prison system, Covid-19.

\title{
Resumem
}

Este artículo tiene como objetivo analizar cómo se está implementando el derecho constitucional a la salud en el contexto de la pandemia Covi-19 en el sistema penitenciario. En Brasil, hay un crecimiento exponencial de la población carcelaria que se ha repetido año tras año, lo que ha provocado un gran colapso en el sistema penitenciario, y al mismo tiempo ha generado descuido por parte de las autoridades como consecuencia de las diversas violaciones. que tienen lugar a diario dentro de las cárceles principalmente en lo que respecta al derecho a la salud en este período pandémico. A partir del surgimiento del contagio del virus, teniendo como principal medida el aislamiento social y el cuidado de la higiene personal, surgió la inquietud por saber cómo se lograrían estas medidas en un entorno de condiciones degradantes como las penitenciarías brasileñas. Para la realización de este estudio se utilizó el método de procedimiento deductivo, la investigación bibliográfica de carácter cualitativo y el uso de la investigación documental. De la investigación se concluyó que la pandemia se vio agravada por la precariedad que ya existe en las cárceles, como el hacinamiento, la falta de estructura, el ambiente insalubre y la falta de equipos médicos multidisciplinarios para asistir en la atención médica de los presos. Se advierte que aun con la creación de políticas para la realización del derecho a la salud de los internos, estas no se ponen en práctica y, a su vez, es necesario que se creen estrategias para que se brinde una provisión positiva del Estado en Prisiones brasileñas, principalmente en este período de la pandemia.

Palabras clave: Derecho a la salud; Sistema penitenciario; Covid-19.

\section{Introdução}

A saúde é um direito constitucional, e deve ser assegurado universalmente a todos cidadãos sem distinção e nesse contexto o direito à saúde no sistema carcerário, precisa de especial atenção por se tratar indubitavelmente de um ambiente discriminado, sem infraestrutura adequada, superlotado onde às pessoas privadas de liberdade ficam à mercê do Estado nesse período de pandemia, e esses fatores são determinantes, o que evidencia a necessidade de se acentuar os esforços do setor saúde na premissa da humanização da atenção (Ferreira et al., 2020).

Nessa senda as consequências gerada em decorrência da superlotação e a falta de estrutura dos presídios favorecem naturalmente a propagação de doenças, enquanto o direito ao acesso à saúde básica continua representando letra morta na legislação e a partir do surgimento do contágio da Covid-19 tendo como principal medida o isolamento social e os cuidados de higiene pessoal, surgiu a preocupação em saber como seria alcançadas essas medidas dentro de um ambiente insalubre como as penitenciarias brasileiras (Souza, 2015).

Em meio a essas questões, é possível levantar o seguinte questionamento: Com as condições de encarceramento precárias devido à falta de estrutura e superlotação dos presídios, como estão sendo efetivados os cuidados para evitar a contaminação pelo vírus da Covid-19 no ambiente carcerário brasileiro?

À vista disso, o presente artigo tem como objetivo principal analisar o direito à saúde no contexto da pandemia dentro do sistema prisional brasileiro correlacionando-a com os seguintes objetivos específicos: Realizar um estudo sobre os aspectos 
gerais do sistema prisional brasileiro, analisar como funciona e é garantido o direito à saúde no sistema carcerário, averiguar os principais impactos da pandemia do Covid-19 para as pessoas encarceradas.

Para a análise de tais fatores, utilizou-se o método de abordagem dedutivo para averiguar como os direitos constitucionais à saúde das pessoas em regime carcerário está sendo efetivados nesse período de pandemia de Covid-19, para tanto realizou-se uma pesquisa bibliográfica de natureza qualitativa através de análise de dados de pesquisas realizadas por institutos, livros, teses, artigos, revistas e por fim foi realizada uma pesquisa documental que foi realizada através da análise de leis e normas que tratam a respeito do direito à saúde no regime prisional.

O manuscrito em tela será dividido em 3 partes, a primeira parte aborda a forma como se deu o surgimento e a insalubridade do sistema prisional brasileiro, enquanto a segunda parte trata da efetivação e aplicação do direito à saúde no sistema carcerário, destacando seus principais desafios e, por fim, a terceira parte correlaciona a pandemia da Covid-19 e a precarização das medidas de saúde no sistema prisional.

Esse estudo pretende colaborar com pesquisas relacionadas à saúde no sistema prisional brasileiro, servindo de fonte de pesquisa que servira de auxílio para trabalhos futuros que versem sobre a efetivação de direitos dos apenados do sistema prisional brasileiro.

\section{O Sistema Carcerário Brasileiro}

De acordo com dados do (Infopen), sistema de informação estatística do Depen (Departamento Penitenciário Nacional) em 2020 o Brasil ocupava o $3^{\circ}$ lugar no ranking de países que possuem a maior população carceraria do mundo. Tendo uma população de 773.151 mil presos (Brasil, 2020).

Esse crescimento exponencial da população carcerária vem acontecendo ano após ano, o que tem provocado um grande colapso no sistema prisional, e ao mesmo tempo isso tem gerado um descaso das autoridades em decorrência das diversas violações que acontecem diariamente dentro das prisões (Menger, 2020).

Em face dos diversos problemas que acontecem por causa do crescimento massivo da população carceraria do país, ocorre concomitantemente a ausência de garantias que assegurem condições mínimas carcerárias, uma vez que oportunamente a falta dessas garantias abre margem para o aumento da violência no interior do sistema prisional, crescimento de grupos criminosos e disseminação de doenças (Azevedo \& Sinhoreto, 2018).

Outro fator que demostra esse crescimento desenfreado aliado a falta de estrutura são os dados de pesquisa realizada pelo infopen no ano de 2019, onde a população prisional estava com um montante de 755.274 pessoas com um total de vagas de 442.349, sendo demonstrado um déficit de 312.925 vagas com uma taxa de ocupação de 170,74\%, entretanto dos 755.274 presos, 30\% são presos provisórios, ou seja, ainda aguardam condenação (Brasil, 2019).

Ademais, a superlotação e essa falta de estrutura dos estabelecimentos prisionais do Brasil, configura várias ofensas ao princípio da dignidade humana que ao mesmo tempo fogem do controle da administração prisional, esses comportamentos devem ser considerados como inaceitáveis aos fundamentos do Estado de Direito, sendo essas condutas consideradas inadmissíveis como preconiza o artigo 40 da LEP- Lei de Execução Penal, "Impõe-se a todas as autoridades o respeito à integridade física e moral dos condenados e dos presos provisórios" (Brasil, 1984).

Em síntese, é perceptível que o sistema carcerário brasileiro sofre de problemas estruturais que não resguardam os direitos fundamentais dos apenados sendo esses problemas aguçados efetivamente por causa da superlotação dos presídios, onde o estado deve tomar as providencias necessárias para futuramente desafogar os presídios e conseguir promover a retribuição, ressocialização, e a promoção das medidas de saúde baseada nos princípios da dignidade humana. 


\section{O Direito Constitucional à Saúde no sistema Carcerário}

A Constituição Federal no seu artigo $5^{\circ}$ prevê um rol de direitos e garantias fundamentais, no tocante ao direito dos encarcerados onde inciso XLIX dita que "é assegurado aos presos o respeito à integridade física e moral" (Brasil, 1988).

Em consonância o seu artigo 196, trata que "a saúde é direito de todos e dever do Estado, garantido mediante políticas sociais e econômicas que visem à redução de doença e de outros agravos e ao acesso universal e igualitário às ações e serviços para sua promoção e recuperação" (Brasil, 1988).

Nesse sentido a efetivação constitucional do direito à saúde é um ato democrático do direito brasileiro, sendo considerado um direito humano e social. Dessa forma a sociedade brasileira é dotada de iniquidades socias as quais estão arraigadas as questões da saúde, em especial no sistema carcerário, e dentro da lógica dos negligenciados do sistema prisional, a partir da saúde no sistema prisional, pode-se dizer que muitos deles não são sequer contabilizados no tocante ao investimento em saúde (Kolling, Silva \& Sá, 2013).

Outrossim, a Carta Magna traz em seu escopo o direito à saúde inserido nos direitos fundamentais (artigo $6^{\mathrm{a}}$ ), bem como na Lei de Execução Penal de 1984 (artigo 11, inciso II) as quais tratam do direito da assistência médica do preso.

Antes da criação da Constituição de 1988, foi criada em 1984 a LEP (Lei de Execução Penal) a qual contêm em seu artigo 14 que a caracterização da "assistência à saúde do preso e do internado de caráter preventivo e curativo compreenderá atendimento médico, farmacêutico e odontológico" (Lage, 2020).

Para garantir que essa assistência médica foi realmente prestada ao apenado a LEP em seu§2 $2^{\circ}$ sustenta ainda que: Quando o estabelecimento penal não estiver aparelhado para promover a assistência médica necessária, esta será prestada em outro local, mediante autorização da direção do estabelecimento (Brasil, 1984).

Em consequência, no ano de 2003 foi aprovado o Plano Nacional de Saúde no Sistema Penitenciário (PNSSP), onde foi elaborada uma proposta para que fosse feita a ampliação da equipe formada por vários profissionais e fossem criadas novas ações de promoção da saúde e de atenção, com o propósito de contribuir para o controle e ou redução das mazelas mais frequentes na saúde da população penitenciária brasileira (Brasil, 2003).

Nesse plano cada equipe de saúde fica responsável por cuidar até 500 presos, já nos estabelecimentos prisionais que tem população de até 100 pessoas, esse atendimento deverá ser realizado em unidades de saúde da rede municipal, respeitando a composição de equipe citada anteriormente, e com carga horária mínima de 4 horas semanais (Jesus, Scarpo, \& Lermen, 2013).

No tocante a essa assistência que é prestada no regime prisional, ainda existe uma grande escassez de recursos para prestação de um atendimento adequado. Isso advém das condições de estruturas do sistema carcerário, somados a falta de profissionais de saúde e da área das ciências humanas para a efetivação de ações multidisciplinares e interdisciplinares para promoção de uma melhoria da saúde física e mental desses cidadãos-presos (Machado \& Guimarães, 2014).

Através dos fatos expostos, percebe-se uma clara contradição, entre a norma escrita e e a sua efetivação na prática, enquanto a Constituição Federal e a Lei de Execução Penal asseguram o direito à saúde, há uma grande dificuldade a sua concretização em decorrência de haver várias lacunas que tornam ineficientes direito à saúde para com os presidiários.

\section{A Pandemia da Covid-19 e o seu Impacto no Sistema Prisional}

$\mathrm{Na}$ contemporaneidade o mundo tem vivenciado um momento atípico causado pela pandemia da Covid-19, a qual foi oficialmente pela Organização Mundial de Saúde em 11 de março de 2020, diante dessa perspectiva sendo considerado o alto índice de transmissibilidade e o agravamento do risco de contágio em lugares com aglomerações de pessoas, o sistema prisional torna assim um lugar insalubre de altíssimo risco, principalmente pelo fato das unidades prisionais não ter as mínimas 
condições para garantir medidas de higiene, muito menos a pratica de isolamento social para os indivíduos sintomáticos (Menger, 2020).

Nesta senda, assim como o mundo o Brasil vive, um de seus momentos mais graves, em relação à saúde pública em paralelo com a economia. Trata-se de um momento delicado por trata-se de uma doença respiratória aguda, identificada pela primeira vez em Wuhan, província de Hubei, na República Popular da China, no final do ano de 2019 (Machado, 2021 ).

Em se tratando da população carceraria, mais de $95 \%$ da população que estava em regime fechado assim permaneceu, de acordo com pesquisa realizada pelo Concelho Nacional de justiça (CNJ), o qual foi concedido como medida de combate ao vírus, regime domiciliar para quarenta e sete mil quinhentos e trinta e cinco mil presos.

Sendo que no mês de outubro de 2020 quando foi contabilizado quatro milhões, novecentos e quinze mil, duzentos e oitenta e nove infectados na população brasileira, dos quais, segundo o Boletim do (CNJ) trinta e oito mil e vinte um ocorreram no interior do sistema carcerário (Pereira \& Ianni, 2020).

No tocante a falta de estrutura, nas penitenciarias faltam constantemente produtos como álcool, água e até sabonete, assim como a alimentação é bastante precária, e em decorrência desse período pandêmico, muitas visitas foram proibidas em diversos estabelecimentos onde muitos apenados deixaram de receber os kits higiênicos trazidos por seus familiares (Lage, 2020).

Diante dessa situação a reflexão feita por Carvalho, Santos e Santos (2020, p. 01) pode funcionar como uma forma de relato em se tratando da saúde no sistema prisional.

Saúde prisional é, em sua essência, saúde pública. A pandemia de Covid-19 representa uma grande ameaça para o mundo e tem demonstrado que prevenir a escalada da doença em prisões faz parte do combate ao novo coronavírus na sociedade em geral. Sabe se, até o momento, que a mais efetiva medida de contenção ao avanço da doença é o isolamento social, no entanto, em instituições penais, muitas vezes superlotadas, tal medida torna-se de difícil implementação e, quando acontece, leva a população privada de liberdade a um superisolamento.

Diante das mazelas apresentadas no texto, nos deparamos no Brasil com o sistema prisional, onde o surto da Covid-19 não pode justificar restrições que constituam tortura ou tratamento cruel, desumano ou degradante, nem devem ser usados para impedir que em um sistema insalubre e superlotado os apenados além de estarem restritos ao sistema prisional sejam impedidos de receberem ajuda de seus familiares (Menger, 2020).

Para se ter uma ideia sobre a situação de superlotação e insalubridade do sistema prisional brasileiro em dezembro de 2019, de acordo com dados disponibilizados pelo Infopen, foram contabilizadas 748.009 pessoas que estavam nas penitenciárias sendo que 222.558 (29,75\%) eram presos provisórios com um total de vagas de 442.349, dessa forma, considerando as unidades prisionais e outras carceragens, o total passa para 755.274. Por conseguinte, diante dessa constatação, não há como manter distanciamento social com presos empilhados em cárceres privados (Brasil, 2020).

Apesar dos vários problemas relatados no sistema carcerário brasileiro o Conselho Nacional de Justiça (CNJ) publicou uma Recomendação de $n^{\circ} 62 / 2020$, com o propósito de tentar diminuir os riscos gerados pela pandemia no sistema carcerário e dentro dessas recomendações, estava previsto a reavaliação das prisões provisórias, dando prioridade às pessoas presas em unidades prisionais cuja capacidade era inferior à ocupação e prioriza também as prisões preventivas e que tenha o prazo ultrapassado de 90 dias ou que seja relacionado a crimes praticados sem violência ou grave ameaça à pessoa.

Outrossim, mesmo com a pratica dessas medidas o próprio CNJ afirmou que os casos de contaminação entre detentos aumentaram em $800 \%$ desde maio de 2020, sendo um dado muito preocupante que impõe medidas urgentes para minimizar as consequências da pandemia em presídios nacionais. 


\section{Resultados e Discussões}

Percebe-se através das pesquisas que no sistema prisional é ausente a pratica de uma política que seja pautada diretamente pelo direito universal à saúde que preconiza a equidade, integralidade, acolhimento e humanização postos pelo SUS, sendo das políticas que precisa ser avaliada é atenção relacionada a distribuição de presos condenados, provisórios, em medida de segurança não se efetiva na prática e que há dificuldade de operacionalizá-la institucionalmente (Ferreira et al., 2020).

Nesse sentido, com a precarização da efetivação das políticas públicas que são oferecidas para minimizar os impactos provocados pelo surto da Covid-19, percebe-se que esse problema é estrutural e vem se perpetuando a muito tempo devido à falta de políticas públicas eficazes que sejam direcionadas especificamente a essas pessoas que vivem em regime carcerário.

Ademais, o distanciamento social, uso de máscaras e de álcool 70\%, medidas para conter o avanço da Covid-19, são altamente difíceis de serem observadas nesses ambientes em decorrência principalmente pela superlotação, falta de produtos de higiene e assistência médica adequada. (Barbosa et al., 2021).

Além da precariedade da assistência à saúde no sistema prisional, ainda existe uma escassez de políticas e recursos para que seja proporcionado um atendimento de qualidade, sendo esses resultados de falta de ambiente adequado para que seja oferecido um atendimento eficaz somando a inexistência de quantitativo eficiente de profissionais de saúde na área para a efetivação de ações multidisciplinares para a melhoria da suade dos cidadãos presos (Machado \& Guimarães, 2014).

Isso se dá principalmente pela falta de planejamento, uma vez que a população carceraria cresce consideravelmente em regime exponencial, fazendo com que haja cada vez mais déficit de vagas e de políticas que são preconizadas em função desse crescimento desregrado o que dificulta ainda mais a prestação de um atendimento médico humanizado no sistema prisional.

Nesse sentido, percebeu-se nesse estudo que o agravamento dos problemas que já existiam anteriormente nas penitenciárias, como a superlotação e a escassez de condições médico-sanitárias satisfatórias, demonstrando uma grande violação aos direitos básicos do ser humano e o não cumprimento das leis constitucionais e infraconstitucionais que tratam dos direitos humanos dos cidadãos.

\section{Considerações Finais}

Diante do estudo, foi possível verificar que o direito à saúde é uma das características da democracia tendo sua efetivação na constituição de 1988, esse direito é considerado como um direito humano e social, dotado de especialidade tendo sua aplicação na sociedade brasileira que é marcada por iniquidades sociais, as quais se tornam muito claras quando o assunto é saúde, especialmente no sistema prisional.

Percebeu também através do estudo, que o problema anteriormente existente na penitenciária, como a superlotação e a escassez de condições médico-sanitárias satisfatórias, aumentou ainda mais em face a pandemia, demonstrando assim a violação aos direitos básicos do ser humano, sendo assim, o distanciamento social, uso de máscaras e de álcool 70\%, medidas para conter o avanço da Covid-19, são altamente difíceis de serem observadas nesses ambientes.

Conclui-se que diante das dificuldades já vivenciadas e agravadas em face da pandemia da Covid-19, torna-se muito difícil atingir um mínimo de garantia dos direitos fundamentais possíveis, no que versem, os poderes garantidores desses direitos fazem a leis e não as efetivam, visto que as recomendações e as providências para adoção de medidas preventivas para diminuir a propagação da infecção provocada pelo vírus no âmbito do sistema de justiça penal não foram implementadas na sua totalidade. 
Research, Society and Development, v. 10, n. 16, e386101620730, 2021

(CC BY 4.0) | ISSN 2525-3409 | DOI: http://dx.doi.org/10.33448/rsd-v10i16.20730

\section{Referências}

Azevedo, R. G. de., \& Sinhoreto, J. (2018). Encarceramento e desencarceramento no Brasil: A mentalidade punitiva em ação. In: 42 ${ }^{\circ}$ Encontro anual ANPOCS. https://www.anpocs.com/index.php/papers-40-encontro3/gt-31/gt21-25/11289-encarceramento-e-desencarceramento-no-brasil-amentalidadepunitiva-em-acao/file.

Barbosa, A. B., Marinho, G. L., \& Costa B, M., (2021). O sistema prisional brasileira frente á pandemia do novo coronavírus (2021). Jornal eletrônico das faculdades integradas junior vianna. https://jefvj.emnuvens.com.br/jefvj/article/view/790/754.

Brasil. (1984). Lei no 7210. Institui a Lei de Execução Penal. http://www.planalto.gov.br/ccivil_03/leis/17210.htm

Brasil. (1988). Constituição da República Federativa do Brasil. Brasília. http://www.planalto.gov.br/ccivil_03/Constituicao/Constituicao.htm.

Brasil. (2019). Ministério da Justiça e Segurança Pública. Departamento Penitenciário Nacional. Sobre o levantamento Nacional. Brasília: Ministério da Justiça e Segurança Pública http://depen.gov.br/DEPEN/depen/sisdepen/infopen/infopen.

Brasil. (2003). Portaria Interministerial no 1.777, de 09 de setembro. https://bvsms.saude.gov.br/bvs/saudelegis/gm/2003/pri1777_09_09_2003.html.

Brasil. (2020). Conselho Nacional de Justiça. O CNJ renova Recomendação $n^{o} 62$ por mais90 dias e divulga novos dados. https://www.cnj.jus.br/cnj-renovarecomendacao-n-62-por-mais-90-dias-e-divulga-novos-dados/.

Brasil. (2020). Infopen. Presos em unidade prisionais no Brasil. Levantamento Nacional de Informações Penitenciárias: dezembro 2019: http://depen.gov.br/depen/sisdepen/infopen/infopen.

Carvalho, S. G. de., Santos, A. B. S. dos., \& Santos, I. M. (2020). A pandemia no cárcere: intervenções no superisolamento. Scielo. https://scielosp.org/article/csc/2020.v25n9/34933502/.

Ferreira, P. A. et al. (2020). Analise do sistema prisional brasileiro: Revisão sistemática sobre a situação da saúde na população privada de liberdade. Humanas e Sociais 8(3). 10.17564/2316-3801.

Jesus, L. O de., Scarpo, K. B. H., \& Lermen, S. H., Beatriz, H. J. O. L. (2013). Desafio os profissionais no campo da saúde no sistema prisional: dilemas na interface entre a saúde e a segurança. versão impressa http://pepsic.bvsalud.org/scielo.php?script=sci_arttext\&pid=S1413-03942013000200004

Kolling, J. G., Silva, B. B. M., \& Sá, P. N.D. C. N. (2013). Direito à Saúde no Sistema Prisional. Rev Tempus Actas Saúde Col. https://www.arca.fiocruz.br/bitstream/icict/41990/2/ve_Gabrielle_Kolling_etal.pdf

Lage, C. C. V., (2020). O direito fundamental à saúde da mulher privativa de liberdade em tempos de covid-19. Revista acadêmica de direito da Unigranrio http://publicações.unigranrio.edu.br/index.php/rdugr/article/view/6322

Machado, G. R. (2021). Pandemia, sistema carcerário e a violação dos direitos humanos Brazilian Journal of Development, Curitiba, 7(5). 10.34117/bjdv7n5-.

Machado, N. O., \& Guimarães, I. S. A. (2014). A Realidade do Sistema Prisional Brasileiro e o Princípio da Dignidade da Pessoa Humana. Revista Eletrônica de Iniciação Científica. 5(1), http:www.univali.br/ricc

Menger, R. L. (2020). O impacto da pandemia do coronavírus no sistema prisional brasileiro Revista Transgressões: ciências criminais em debate, 8(2), dezembro. file:///C:/Users/santo/Downloads/22352-Texto\%20do\%20artigo-77647-1-10-20210129\%20(6).pdf.

Pereira, L. J. C., \& Ianni, C. G. de; (2020) Pandemia e indignidade: O corona virus e o estado de coisas inconstitucional do sistema carcerário brasileiro. Ciências Criminais em Perspectiva, 1(1). https://www.sumarios.org/artigo/pandemia-de-indignidade-o-coronav\%C3\%ADrus-e-o-estado-de-coisasinconstitucional-do-sistema.

Souza, G. A. (2015). Analise jurídica do sistema penitenciario brasileiro à luz dos tratados internacionais em direitos humanos. Revista Direito em Ação, Brasília, 14(1). https://portalrevistas.ucb.br/index.php/RDA/article/view/6709. 